\title{
PENERAPAN MODEL PEMBELAJARAN KOOPERATIF TYPE STAD UNTUK MENINGKATKAN HASIL BELAJAR MATEMATIKA SISWA KELAS V SD NEGERI 006 SUNGAI BULUH KECAMATAN SINGINGI HILIRTAHUN PELAJARAN 2019/2020
}

\author{
JAYUS \\ SD Negeri 006 Sungai Buluh \\ Jay150986@yahoo.co.id
}

\begin{abstract}
ABSTRAK
Penelitian ini bertujuan untuk mengetahui apakah penerapan model pembelajaran kooperatif type STAD dapat meningkatkan hasil belajar siswa pada mata pelajaran Metematika. Ini senada dengan pernyataan Slavin (1995) bahwa salah satu fungsi model pembelajaran type STAD adalah meningkatkan tanggung jawab individu maupun kerja kelompok. Kondisi ini akan meningkatkan minat belajar dan keaktifan siswa di dalam kelas yang pada gilirannya dapat meningkatkan hasil belajarnya.

Hasil Penelitian menunjukkan aktivitas guru pada siklus I adalah 23 dengan kategori sempurna, pada siklus II meningkat menjadi 27 dengan kategori sangat sempurna. Untuk aktivitas siswa pada siklus I adalah 81 dengan kategori tinggi dan pada siklus II meningkat menjadi 105 dengan kategori sangat tinggi. Dan mengenai hasil bealajar siswa pada siklus I rata-rata kelasnya adalah 73,04 dengan kategori sedang pada siklus II meningkat menjadi 79,04 dengan kategori tinggi. Dengan ini menandakan bahwa dengan Penerapan Model Pembelajaran Kooperatif Type STAD dapat meningkatkan hasil belajar Matematika siswa kelas VI SD Negeri 006 Sungai Buluh Kecamatan Singingi HilirTahunPelajaran 2019 / 2020.
\end{abstract}

Kata Kunci : Model Pembelajaran, Kooperatif Type Stad, Hasil Belajar

\section{PENDAHULUAN}

Dalam kamus Besar Bahasa Indonesia diterangkan bahwa Model adalah pola atau acuan dari sesuatu yang akan dibuat atau dihasilkan (KBBI, 1999:662) Dan Komaruddin dalam Ensiklopedia Manajemen menyebutkan " Model adalah penggambaran hubungan diantara variabel-variabel yang saling mempengaruhi sehingga menunjukkan suatu sistem atau proses, baik sebagai keseluruhan maupun sebagian dari keseluruhan tersebut". ( Komaruddin, 1994:573 ) Chauhan mengatakan Model Pembelajaran adalah merupakan sebuah perencanaaan pengajaran yang menggaambarkan proses yang ditempuh pada proses belajar mengajar agar dicapai perubahan spesifik pada prilaku siswa seperti yang diharapkaan. (Abdul Aziz Wahab, 2007:52 ). Menurut Joyce (dalam Trianto, 2007:5) mengemukakan yang dimaksud Model Pembelajaran adalah Suatu perencanaan atau suatu pola yang digunakan sebagi pedoman dalam merancanakan pembelajaran dikelas atau pembelajaran dalam tutorial dan untuk menentukan perangkat-perangakat pembelajaran termasuk di dalamnya buku-buku, film, computer, kurikulm dan lain-lain. Sedangkan Soekomto (dalam Trianto, 2007:5) mengemukakan maksud dari model Pembelajaran adalah "Kerangka 
konseptual yang melukiskan prosedur yang sistematis dalam mengorganisasikan pengalaman belajar untuk mencapai tujuan belajar tertentu dan berfungsi sebagai pedoman bagi para perancang pembelajaran dan para pengajar dalam merencakan aktivitas belajar mengajar".

Berdasarkan pendapat diatas dapat disimpulkan bahwa model pembelajaran adalah suatu perencanaan yang menggambarkah langkah-langkah proses pembelajaran yang akan dijalankan dalam kegiatan belajar mengaja. Menurut Slavin ( 1995 ) Model Pembelajaran Coopertive adalah model pembelajaran dengan penekanan pada aspek sosial dalam belajar dengan menggunakan kelompok-kelompok kecil terdiri dari 4-6 orang siswa yang hetorogen \{ jenis kelamin/kemampuan ) untuk mencapai tujuan. (Zainal Aqib, 2007:71) Model Pembelajaran Cooperatif Type STAD ( Student Team Achiement Devision ) Tim siswa kelompok prestasi merupakan model belajar memupuk pembentukan kelompok kerja dengan lingkungan positif, meniadakan persaingan individu dan isolasi lingkungan akademik. Terdapat tiga konsep utama yang menjadikan karakteristik pembelajaran kooperatif type STAD yaitu (1) penghargaan kelompok (2) pertanggung jawaban indiviu (3) kesempatan yang sama untuk berhasil. Para siswa dalam kelompok kecil dan menggunakan lembaran kerja untuk menguasai suatu cabang pengetahuan. Meraka saling membantu diantar satu sama lain melalui tutorial. Kuis atau perbincangan kumpulan. (Depdiknas Model Pembelajaran. Co. id, tanpa tahun: slid 9)

Langkah-langkah Pelaksanaan Model Pembelajaran Type STAD ini didasarkan pada langkah-langkah cooperative yang terdiri atas enam langkah atau fase seperti yang tersaji dalam table 2.1 berikut ini:

Tabel 1. Fase-fase Pembelajaran Ooperatif Type STAD

\begin{tabular}{|l|l|}
\hline \multicolumn{1}{|c|}{ Fase } & \multicolumn{1}{|c|}{ Kegiatan Guru } \\
\hline $\begin{array}{l}\text { Fene 1 } \\
\text { memotivasi siswa }\end{array}$ & $\begin{array}{l}\text { Menyampaikan semua tujuan pembelajaran yang } \\
\text { memotivasi siswa belajar } \\
\text { Fase 2 }\end{array}$ \\
$\begin{array}{l}\text { Menyajikan / Menyampaikan } \\
\text { informasi }\end{array}$ & $\begin{array}{l}\text { Menyajikan informasi kepada siswa dengan jalan } \\
\text { mendemontrasikan atau lewat bahan bacaan. }\end{array}$ \\
Fase 3 & $\begin{array}{l}\text { Menjelaskan kepada siswa bagaimana caranya } \\
\text { membentuk kelompok belajar dan membantu }\end{array}$ \\
\hline
\end{tabular}




\begin{tabular}{|l|l|}
\hline $\begin{array}{l}\text { Mengorganisasikan siswa } \\
\text { dalam kelompok-kelompok } \\
\text { belajar }\end{array}$ & $\begin{array}{l}\text { setiap kelompok agar melakukan transisi secara } \\
\text { efisien. }\end{array}$ \\
Fase 4 & $\begin{array}{l}\text { Membimbing kelompok-kelompok belajar pada } \\
\text { saat mereka mengerjakan tugas mereka. }\end{array}$ \\
$\begin{array}{l}\text { Membimbing } \\
\text { bekerja dan belajar }\end{array}$ & $\begin{array}{l}\text { Mengevaluasi hasil belajar tentang materi yang } \\
\text { telah diajarkan atau masing-masing kelompok } \\
\text { mempersentasikan hasil kerjanya }\end{array}$ \\
Fase 5 & $\begin{array}{l}\text { Mencari cara-cara untuk menghargai baik upaya } \\
\text { maupun hasil belajar individu dan kelompok }\end{array}$ \\
Fvaluasi & 6
\end{tabular}

( Sumber: Ibrahim dalam Trianto, 2007:54 )

Kelebihan / keunggulan Model Pembelajaran Type Stad : a. Mendorong siswa untuk berpikir secara ilmiah dan kreatif. b. Melatih siswa untuk belajar dengan tutor sebaya c. Merangsang kreativitas anak didik dalam bentuk ide, gagasan-prakarsa, dan terobosan baru dalam pemecahan masalah. d. Mengembangkan sikap menghargai pendapat orang lain. e. Memperluas wawasan $\mathrm{f}$. Membina terbiasa musyawarah untuk mufakat dalam memecahkan masalah. g. Meningkatkan tanggung jawab individu maupun kerja kelompok.

Model pembelajaran kooperatif type STAD memungkin timbulnya komunikasi dan interaksi yang lebih berkualitas antara siswa dengan siswa dalam kelompok maupun siswa dengan siswa antar kelompok. Model pembelajaran kooperatif type STAD dapat membantu siswa memahami mata pelajaran Matematika, karena model pembelajaran ini memiliki dampak positif terhadap hasil belajar yang rendah. Selain itu pada model pembelajaran type STAD ini keberhasilan siswa dianggap tanggung jawab bersama. Pada model pembelajaran ini akan diketahui perkembangan individu karena model ini menghitung skor dari skor dasar. Dengan adanya pengumuman skor yang dilakukan oleh guru akan meningkatkan kreatifitas bersaing anak dalam belajar sehingga dapat meningkatkan peningkatan ketuntasan belajar anak di sekolah. 


\section{METODE PENEILITIHAN}

Peneliti perbaikan pembelajaran ini dilaksanakan di SD Negeri 006 Sungai Buluh Kecamatan Singingi Hilir Kabupaten Kuantan Singingi Hilir, dengan siswa yang berjumlah 24 orang siswa terdiri dari siswa 10 orang siswa laki-laki dan 14 orang siswa perempuan. Dan Waktu pelaksanaan penelitian perbaikan pembelajaran ini dilakukan mulai tanggal 15 Agustus sampai dengan 20 September 2019.

Dalam penelitian ini pengumpulan datanya dilaksanakan dengan menggunakan teknik tes, yaitu tes tertulis dalam bentuk pilihan ganda dan uraian singkat, untuk mengetahui efektifitas jalannya pembelajaran digunakan teknik observasi atau pengamatan, untuk mengetahui sejauhmana peningkatan motivasi dan hasil belajar siswa digunakan teknik analisis data/dokumen, dan untuk mengetahui kesulitan kesulitan belajar siswa digunakan Teknik wawancara dan diskusi.. Sedang alat yang digunakan untuk pengumpulan data adalah: (a) Dokumentasi, (b) Observasi, dan (c) Tes tertulis.

Data yang berhasil dikumpulkan dari penelitihan ini bersifat data kualitatif dan data kuantitatif. Data kualitatif adalah data yang berupa hasil pengamatan maupun hasil wawancara serta refleksi dari tiap-tiap siklus yang telah dianalisis dengan menggunakan analisis deskriptif kualitatif. Sedangkan untuk data kuantitatif adalah data berupa nilai tes setelah siklus I, dan setelah siklus II yang dianalisis menggunakan analisis deskriptif komparatif. Analisis tersebut dilakukan dengan cara membandingkan nilai tes kondisi awal, nilai tes setelah siklus I, dan nilai tes setelah siklus II, kemudian direfleksi.

Prosedur Pelaksanaan Penelitian Tindakan Kelas ini dilakukan dalan 2 siklus di mana tiap tiap siklus dilaksanakan sesuai dengan indikator yang akan dicapai dan hasil tiap tiap siklus direfleksi dan hasilnya digunakan untuk menentukan langkah-langkah perbaikan selanjutnya. Dan tahapan dilaksanakan dalam penelitihan ini meliputi: (1) Perencanaan, (2) Pelaksanaan, (3) Pengamatan, dan (4) Refleksi.

\section{HASIL PENELITIAN DAN PEMBAHASAN}

Hasil Belajar siswa dalam Penerapan Model Pembelajaran Kooperatif Type STAD pada perbaikan pembelajaran Matematika terjadi peningkatan penguasaan siswa terhadap materi pembelajaran. Sebagaimana dapat dilihat pada tabel dibawah ini.

Tabel 2. Rekap Hasil Nilai matematika Siswa Kelas V SD Negeri 006 Sungai Buluh dengan Penerapan Model Pembelajaran Kooperatif Type STAD Pada Siklus I dan Siklus II

\begin{tabular}{|c|c|c|c|c|l|}
\hline \multirow{2}{*}{$\begin{array}{c}\text { Rentang } \\
\text { Nilai }\end{array}$} & \multirow{2}{*}{ Kategori } & \multicolumn{2}{|c|}{ Frekuensi / Persentase } & \multirow{2}{*}{ Ket } \\
\cline { 3 - 5 } & & Pebelum & \multicolumn{2}{|c|}{ Sklus } & \\
\cline { 3 - 6 } & & - & - & 2 & Tuntas \\
$80-100$ & $\begin{array}{c}\text { Sangat baik } \\
\text { sekali }\end{array}$ & - & 6 & 12 & Tuntas \\
\hline
\end{tabular}




\begin{tabular}{|l|c|c|c|c|l|}
\hline $70-79$ & Baik sekali & 6 & 13 & 9 & Tuntas \\
$60-69$ & Baik & 14 & 5 & 1 & T.Tuntas \\
$50-59$ & Cukup & 3 & - & - & T.Tuntas \\
$<50$ & Kurang & 1 & - & - & T.Tuntas \\
& Sangat kurang & & & & \\
\hline Jumlah Yang Tuntas & 6 & 19 & 23 & \\
\hline Jumlah Tidak Tuntas & 18 & 5 & 1 & \\
\hline Rata-rata kelas & 62.29 & 73.04 & 79.04 & \\
\hline Prosentase Ketuntasan & $25 \%$ & $79.17 \%$ & $95.83 \%$ & \\
\hline
\end{tabular}

Dari tabel diatas dapat dilihat, bahwa pencapaian hasil belajar siswa pada mata pelajaran Matematika sebelum pelaksanaan perbaikan pembelajaran siswa yang mencapai KKM hanya 6 orang siswa $(25 \%)$ dari 24 orang siswa. Setelah dilaksanakan perbaikan pembelajaran pada siklus I siswa yang mencapai ketuntasan sebanyak 19 orang siswa atau $79.177 \%$ dan masih terdapat 5 orang siswa yang belum mencapai ketuntasan. Hasil pelaksanaan pembelajaran pada siklus Pertaman direfleksi dan didiskusikan bersama supervisor untuk mengetahui dimana letak kekurangan dan kelemahan proses pembelajaran pada siklus pertama kemudian dicari solusi untuk perbaikan pada pembelajaran siklus kedua. Ternyata setelah pelaksanaan perbaikan pembelajaran pada siklus II yang mencapai ketuntasan miningkat menjadi 23 orang siswa, hanya tinggal 1 orang siswa (4.14\%) yang belum tuntas. Ini menunjukkan bahwa Penerapan Model Pembelajaran Kooperatif Type STAD dalam proses pelaksanaan pembelajaran dapat mempengaruhi keberhasilan belajar siswa, dalam kata lain Penerapan Model Pembelajaran Kooperatif Type STAD dapat meningkatkan hasil belajar siswa. Hasil belajar tersebut bila ditampilkan dalam grafik akan tampak seperti grafik berikut:

Grafik 1 : Hasil Belajar Matematika Kelas V SD Negeri 006 Sungai Buluh dengan Penerapan Model Pembelajaran Kooperatif Type STAD.

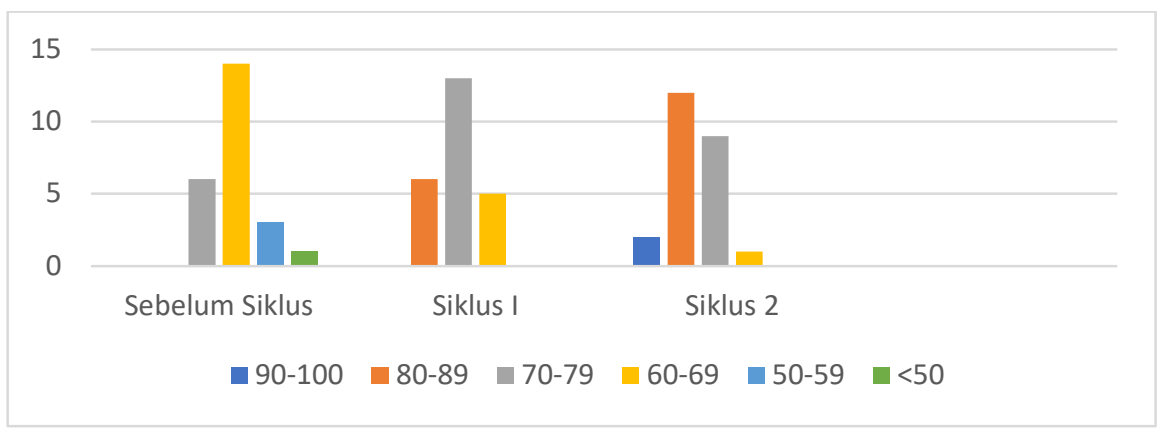


Untuk aktivitas siswa menurut observasi secara umum sudah menunjukkan minatnya untuk belajar yang sangat tinggi. Dan untuk mengetahui rata-rata aktivitas siswa dalam Penerapan Model Pembelajaran Kooperatif Type STAD dan alat peraga dapat dilihat pada tabel 3 sebagai berikut: :

Tabel 3. Rekapitulasi Aktivitas Belajar Siswa Kelas V SD Negeri 006 Sungai Buluh dengan Penerapan Model Pembelajaran Kooperatif Type STAD Pada Siklus I dan

Siklus II

\begin{tabular}{|c|l|c|c|c|c|}
\hline \multirow{2}{*}{ No } & \multicolumn{2}{|c|}{ Aktivitas yang Diamati } & \multicolumn{2}{c|}{ Siklus I } & \multicolumn{2}{c|}{ Siklus II } \\
\cline { 2 - 6 } & Aktivitas & $\%$ & Aktivitas & $\%$ \\
\hline 1 & $\begin{array}{l}\text { Mendengarkan penjelasa guru } \\
\text { dengan serius }\end{array}$ & 19 & $79 \%$ & 23 & $96 \%$ \\
\hline 2 & Mencatat penjelasan guru & 16 & $67 \%$ & 19 & $79 \%$ \\
\hline 3 & Menanyakan kesulitan & 14 & $58 \%$ & 21 & $88 \%$ \\
\hline 4 & Aktif dalam kelompok dengan & 14 & $58 \%$ & 20 & $83 \%$ \\
\hline 5 & $\begin{array}{l}\text { Melaksanakan tugas } \\
\text { tekun }\end{array}$ & 81 & & 105 & $92 \%$ \\
\hline & Jumlah aktivitas siswa & $68 \%$ & & $88 \%$ \\
\hline
\end{tabular}

Berdasarkan hasil pengamatan Supervisor melalui lembar pengamatan yang terangkum pada tabel 3.2 diatas aktivitas siswa menunjukkan adanya peningkatan seperti tampak pada lembar pengamatan aktivitas siswa, secara keseluruhan aktivitas siswa pada siklus pertama ini mencapai 81 dari total skor tertinggi 120. Dan setelah berdiskusi dengan Supervisor serta memdapat saran dari Supervisor kekurangan pada siklus ke pertama dapat diperbaiki dan ditingkatkan pada pelaksanaan siklus kedua, hal ini tampak pada lembar pengamatan aktivitas siswa yang diisi oleh Supervisor telah menunjukkan peningkatan aktivitas siswa pada semua aspek. Dan secara keseluruhan sudah mencapai 105 dari skor tertinggi 120, berarti dari siklus pertama sampai siklus kedua mengalami peningkatan 24 skor.

Dari laporan Supervisor dapat diperoleh gambaran tentang aktivitas guru dalam melaksanakan perbaikan pembelajaran sebagaimana tergambar pada Tabel 4. berikut:

Tabel 4. Rekapitulasi Aktivitas Guru Dalam Melaksanakan Perbaikan Pembelajaran Pada Siklus I dan Siklus II

\begin{tabular}{|c|l|c|c|c|c|}
\hline \multirow{2}{*}{ No } & \multirow{2}{*}{ Pelaksanaan Aktivitas } & \multicolumn{2}{|c|}{ Siklus 1} & \multicolumn{2}{c|}{ Siklus 2 } \\
\cline { 3 - 6 } & & Jumlah & Skor & Jumlah & Skor \\
\hline 1 & Sangat baik & 4 & 16 & 6 & 24 \\
\hline 2 & Baik & 2 & 6 & 1 & 3 \\
\hline
\end{tabular}




\begin{tabular}{|c|l|c|c|c|c|}
\hline 3 & Cukup & 1 & 2 & - & - \\
\hline 4 & Tidak dilaksanakan & - & - & - & - \\
\hline \multicolumn{2}{|c|}{ Jumlah } & 7 & 24 & 7 & 27 \\
\hline
\end{tabular}

Dari tabel diatas dapat dilihat bahwa dalam pelaksanaan proses perbaikan pembelajaran yang dilakukan oleh peneliti dari mulai siklus I sampai siklus II, aktiviatas guru selalu meningkat, karena kekurangan-kekurangan ada selalu direfleksi oleh supervisor dan dicari solusi perbaikannya. Sehingga semua kesalahan dan kekurangannya dapat diperbaiki, sebagaimana telihat dalam lampiran kativitas guru sebagai berikut:

\section{KESIMPULAN}

Dalam pelaksanaan perbaikan pembelajaran Matematika tentang operasi penjumlahan dan pengurangan pecahan dengan Penerapan Model Pembelajaran Kooperatif Type STAD dapat memotivasi siswa untuk berperan aktif dalam proses pembelajaran yang akhirnya dapat meningkatkan hasi belajar siswa atau peningkatan penguasaan terhadap materi pembelajaran Matematika di kelas V SD Negeri 006 Sungai Buluh Kecamatan Singingi Hilir. Peningkatan penguasaan materi atau hasil belajar siswa ini dapat dilihat : 1) Dari hasil belajar Nampak adanya peningkatan, sebelum perbaikan rata-rata kelasnya hanya 62,29 Setelah diadakan perbaikan mengalami peningkatan yaitu pada siklus I mencapai 73,04 dan pada siklus II menjadi 79.04. 2) Dilihat dari ketuntasan belajar, sebelum perbaikan siswa yang tuntas hanya 6 orang atau $25 \%$ setelah diadakan perbaikan pada siklus I siswa yang tuntas 19 orang atau $79.17 \%$ dan pada siklus II yang tuntas mencapai 23 orang atau 95,83\%.3) Aktivitas siswa juga mengalami peningkatan pada siklus I mencapai skor 81 dan siklus II meningkat menjadi 105 Dari total skor 120. 4) Dan aktivitas guru pun juga mengalami peningkatan yaitu pada siklus I mencapai skor 24 dan pada siklus II mencapai skor 27 dari jumlah skor 28.

Dengan demikian Penerapan Model Pembelajaran Kooperatif Type STAD ini tidak hanya meningkatkan hasil belajar siswa, meningkatkan ketuntasan dan aktivitas siswa, tetapi juga meningkatkan kemampuan guru dalam menerapkan suatu metode pembelajaran khususnya Penerapan Model Pembelajaran Kooperatif Type STAD.

\section{DAFTAR PUSTAKA}

A. Syaiful, 2003, Proses Belajar Mengajar, Bandung, Remaja Rosdakarya

Departemen Pandidikan dan Kebudayaan, 1999. Kamus Besar Bahasa Indonesia, Jakarta, PT. Balai Pustaka

Departemen Pendidikan Nasional, Model Pembelajaran. Co.id, tanpa tahun: slid 9

Departemen Pendidikan Nasional, 1995, Petunjuk Pelaksanaan Kegiatan Belajar Mengajar, Jakarta, Balitbang Depdiknas.

Depdikbud, 1995, Dikdakdik/Metodik Umum, Jakarta

Hamalik, 2007. Proses Belajar Mengajar, Jakarta. Bumi Aksara 
Jayus, 2008, Penggunaan Model Pembelajaran STAD Untuk Menngkatkan Hasil Belajar Siswa Kelas VI SD Negeri 014 Suka Maju Kecamatan Singingi Hilir Hilir

Karso Dkk, 2003 "Pendidikan Matematika I Jakarta Universitas Terbuka "

Komaruddin, 1994. Ensiklopedia Manajemen, Bandung, Bumi Aksara

Syah Muhibin, 1997. Spikologi Pendidikan dengan Pendekatan Baru, Bandung.

Trianto, 2007, Model Model Pembelajaran Inovatif Berorientasi Konstruktivistik, Surabaya, Prestasi Pustaka

Zainal Aqib, 2007, Membangun Profesionalisme Guru dan Pengawas Sekolah, Bandung, Yrama Wid 